


\section{La $56^{\mathrm{a}}$ Bienal de Venecia. All the worlds futures: cuestionando y desplegando la exhibición}

José-Carlos Mariátegui Ezeta

Instituto de Investigaciones Museológicas y Artísticas de la Universidad Ricardo Palma

Este artículo reseña la 56a Bienal de Venecia 2015, comisariada por Okwui Enwezor. En primer lugar presentamos una breve historia de la Bienal de Venecia y los procesos que en las últimas décadas le otorgaron su configuración actual. Luego, analizamos el concepto curatorial de la 56a edición, donde El Capital de Marx es utilizado como instrumento crítico para desplegar una reflexión sobre el impacto del arte en la sociedad actual. Para ilustrar este punto destacamos algunas de las obras seleccionadas por Enwezor, así como una breve descripción de algunos pabellones nacionales. Posteriormente, incidimos sobre la destacada representación peruana. Concluimos con un análisis sobre la 56a Bienal, con énfasis en su formato de exhibición y en el papel social y crítico del arte en el siglo XXI.

Palabras clave: Bienal de Venecia, Okwui Enwezor, Karl Marx, Perú, exhibición, arte y sociedad

This article reviews the $56^{\text {th }}$ Venice Biennale 2015, curated by Okwui Enwezor. First we give a brief history of the Venice Biennale and the processes that it went through in the last decades which defined its current configuration. Then, we explore the $56^{\text {th }}$ edition's curatorial concept, that uses Marx's Capital as a critical tool to unfold a reflection about the impact of art in current society. To illustrate this point, we briefly highlight some works selected by Enwezor as well as a brief description of some national pavilions. Subsequently, we emphasize on this year's outstanding Peruvian representation. We conclude with an analysis of the $56^{\text {th }}$ Biennial, with an emphasis on both its exhibition format as well as the social and critical role of art in the XXI century.

Keywords: Venice Biennale, Okwui Enwezor, Karl Marx, Peru, exhibition, art and society

\section{Preámbulo Histórico}

La Bienal de Arte de Venecia, también conocida como la "Exhibición Internacional de Arte", se inició en el año 1895 y consistía originalmente en un conjunto de pabellones nacionales que representaban a un número limitado de países, así como algunas exhibiciones especiales. Podríamos decir que en las últimas décadas, dos procesos importantes ayudaron a renovar su trascendencia internacional. El primero, tuvo que ver con los escenarios políticos y sociales en el mundo a partir de los años 60 y la función del arte y los artistas presentes en la Bienal como instrumentos de crítica y transformación social. Dos hechos históricos ejemplifican dicho proceso y su impacto en la Bienal: En 1968, un grupo de activistas políticos y estudiantes tomaron los pabellones nacionales en señal de protesta por la guerra de Vietnam; luego, en 1974, la Bienal estuvo dedicada a Chile en incuestionable solidaridad por el golpe de Estado a Salvador Allende. El segundo proceso, fue la internacionalización 
del arte en la Bienal: para el año 1980, el crítico de arte italiano Achille Bonito Oliva y el curador suizo Harald Szeemann, introdujeron dentro de la Bienal el Aperto, un nuevo formato que incorporaba prácticas artísticas de zonas geográficas poco representadas o “emergentes”, lo que renovó el carácter universalista de la Bienal en épocas de globalización. Sucesivamente, Szeemann, en su condición de director artístico de la Bienal, en los años 1999 y 2001, impulsa formalmente la incorporación de artistas internacionales lo que favoreció también la ampliación del espacio de exhibición a la zona del Arsenale ${ }^{1}$. Podemos decir que estos dos procesos le dan a la Bienal de Arte de Venecia su configuración actual y nos permitirán contextualizar la línea curatorial propuesta por Okwui Enwezor (Fig. 1) para la $56^{\mathrm{a}}$ edición.

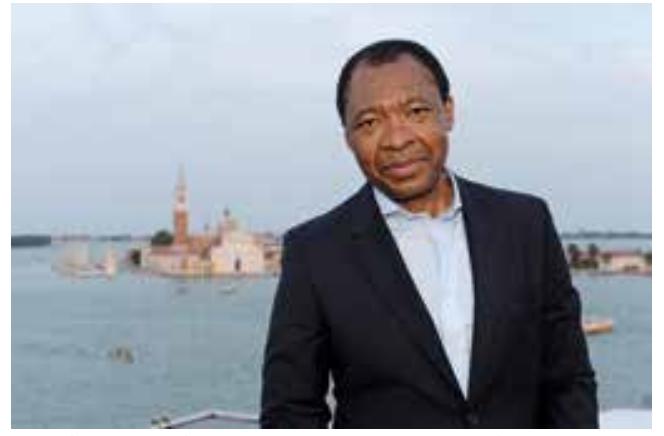

Fig. 1. Okwui Enwezor, curador de la 56va Bienal. 56th International Art Exhibition. Foto: Giorgio Zucchiatti. Cortesía: Bienal de Venecia.

56 Bienal: Todos los Futuros del Mundo Bajo el título All the Worlds Futures ("Todos los Futuros del Mundo”) la 56 $6^{\text {a }}$ Bienal buscó generar una discusión crítica sobre el carácter transformador y social del arte en épocas de internacionalización y cómo éste viene respondiendo a los temas apremiantes del presente siglo en el mundo como son el calentamiento global, el impacto tecnológico y el poder económico-financiero-social que ejercen los mercados y empresas. Para ello, Enwezor resignificó la discusión sobre de El Capital de Karl Marx mediante la obra Das Kapital Oratorio, proyecto artístico dirigido por Isaac Julien donde actores escenificaron, en tono dramático, la lectura completa de la obra central de Marx a lo largo de los meses de duración de la Bienal. La Arena, espacio diseñado por el arquitecto ghanés-británico David Adjaye dentro del Pabellón Central ${ }^{2}$ de I Gardini fue el lugar escogido para esta relectura contemporánea de El Capital que quedará signada como uno de los eventos emblemáticos de la $56^{\text {a }}$ Bienal. Enwezor intentó así propiciar una consistencia histórica y política y, similar a la ya mencionada Bienal de 1974, buscó con la Arena generar un espacio dinámico y crítico a la vez, de performances, debates y conferencias en torno al papel social del arte (Enwezor, 2015: 017-117). Las actividades que se dieron lugar en la Arena y en otros espacios compusieron el cuerpo vivo de la Bienal, expandiendo el formato de la exhibición a una dinámica cambiante y de constante discusión crítica.

Resulta importante analizar las razones por las que Enwezor utiliza El Capital como concepto curatorial para generar una reflexión sobre el carácter transformador y social del arte. Para ello es interesante revisar las primeras páginas del catálogo de la Bienal donde se presentan, en facsímile y de forma consecutiva, imágenes de la edición original de $E l$ contrato social de Jean-Jacques Rousseau (1762), un manuscrito de Karl Marx con anotaciones sobre El contrato social, la primera edición de El Capital de Marx y, finalmente, las carátulas de dicha obra en diversas lenguas extranjeras. Esta secuencia vinculante nos permite reflexionar sobre la importancia de la historia y cómo ésta permite construir modelos de reflexión social que tienen un impacto sobre la realidad actual. Es por ello que la función de El Capital en la 56 ${ }^{\mathrm{a}}$ Bienal es doble: utilizarlo como un método de interpretación de un arte

1 El Arsenale, al igual que I Gardini, está circundado por pabellones nacionales pero en este caso son países con presencia reciente en Venecia, como son Emiratos Árabes Unidos, México, Argentina, Turquía, Sudáfrica, Chile y Perú.

2 También conocido como el Pabellón Italiano. 
que dialogue con los problemas más apremiantes en el mundo para generar una dialéctica sobre "el estado de las cosas", analizando el progreso no solo como generador de riqueza sino también de destrucción y desigualdad. Y, desde una perspectiva histórica, el concepto curatorial busca ilustrar que muchas de las discusiones generadas hace décadas en el mundo del arte mantienen vigencia y son herramientas críticas para entender la actual coyuntura donde la materialidad está adquiriendo características "inmateriales", signadas por la incesante capacidad de actualización de la información tecnológica que da lugar.

Similar al trabajo desplegado como curador de Documenta11, Enwezor propone para la $56^{\mathrm{a}}$ Bienal la generación de "plataformas de discusión"3 para enriquecer y ampliar la reflexión artística sobre "la situación actual de las cosas" y la "apariencia de las cosas". Para ello articuló proyectos de reflexión intelectual como el e-flux journal SUPERCOMMUNITY y el Creative Time Summit. El equipo de e-flux journal (Nueva York, 2008), la reconocida plataforma de publicación y distribución de noticias sobre el mundo del arte, publica desde el año 2008 ensayos especialmente comisionados sobre "paradigmas culturales, políticos y estructurales que informan a la producción artística contemporánea"4. Para la Bienal, e-flux journal desarrolló SUPERCOMMUNITY5 una revista y foro de opiniones de acceso digital gratuito que publicó diariamente, durante cuatro meses, un artículo, idea, proyecto u opinión sobre temáticas contemporáneas apremiantes como son: Corrupción, Cosmos, Computación Planetaria, Apocalypsis, Políticas del Brillo, El Arte del Trabajo, el "Arte", el Social Commons y Cuba (en momentos del restablecimiento, después de medio siglo, de las relaciones diplomáticas entre dicho país y los Estados Unidos). Por otro lado, la organización Creative Time (Nueva York, 1975) llevó a cabo el $7^{\circ}$ Creative Time Summit ${ }^{6}$ que buscó expandir los temas sobre educación utilizando el concepto de curriculum mediante discusiones y conferencias ${ }^{7}$ en cuatro tópicos sugerentes que buscaron poner en cuestionamiento la creación y difusión de conocimiento hoy: la institución educativa como forma, la geografía de aprendizaje, el arte de la pedagogía, y el conocimiento como una experiencia colectiva.

\section{Desplegando una exhibición multi-temporal: Artistas participantes}

La exhibición de la $56^{\text {a }}$ Bienal debe ser vista como "capas" donde se desplegaron obras de múltiples tiempos históricos. Los proyectos de 136 artistas internacionales seleccionados incluyeron tanto obras recientes como históricas, lo que permite relacionar, reinterpretar y analizar el significado de la producción artística desde perspectivas multitemporales. Esta característica vinculó películas de Sergei Eisenstein (Latvia, 1898) o fotografías de Walker Evans (Missouri, 1903) con los dibujos de Samson Kambalu (Malawi, 1975), y complementarlas con las instalaciones del colectivo Raqs Media Collective (Delhi, 1992) y los recientes manifiestos del Gulf Labor Coalition (Nueva York, 2010) ${ }^{8}$. Este ensamble multi-temporal se entrelazó con homenajes, como al recientemente fallecido Harun Farocki (República Checa, 1944) de quien se presentó un "atlas” de su obra contenida en 87 películas.

La asociación entre pasado y presente vinculada al "estado de las cosas" demanda un lente analítico y reflexivo que convirtió a la exhibición en una máquina de pensamiento dinámico

3 Como curador de Documenta11, Enwezor propuso cinco "plataformas" con conferencias, debates y talleres alrededor del mundo que concluyeron con la exhibición en Kassel (Plataforma 5).

4 http://www.e-flux.com/about/

5 http://supercommunity.e-flux.com/.

6 http://creativetime.org/summit/venice-2015/ (10-13 de agosto, 2015).

7 Todas las conferencias están disponibles en Internet en: http://creativetime.org/summit/presentations/ .

8 Una coalición de artistas internacionales que velan por las condiciones de trabajo durante la construcción de los museos de la isla Saadiyat en Abu Dhabi (http://gulflabor.org/). 


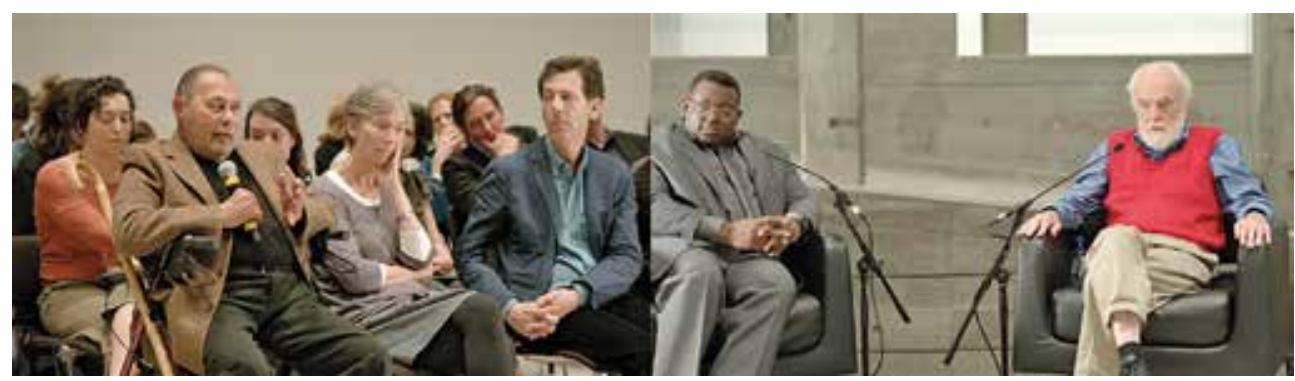

Fig 2. Isaac Julien (Londres, 1960). KAPITAL (2013), video instalación de dos canales en alta definición con sonido estéreo (duración: 31'16"). Cortesía: el artista y Victoria Miro Gallery, London.

que imbricó entre la historia y la actualidad, y que propuso replantear la noción de la exhibición tradicional, transformándola en un foro y espacio público. En un mundo que está hambriento de significados nuevos, la exhibición formal de arte como formato de descubrimiento y aprendizaje ha demostrado tener un límite y como respuesta Enwezor propuso "desplegar" la exhibición con obras actuales e históricas y complementarlas con actividades que la enriquezcan y la evolucionen hacia una exhibición dialogante, crítica y viva.

Una obra que mediatizó particularmente con esta reflexión fue la video instalación titulada KAPITAL (Fig. 2), también de Julien ${ }^{9}$, donde vemos al autor debatiendo sobre el impacto actual de El Capital con el escritor marxista David Harvey (autor del libro El Enigma del Capital) frente a una audiencia ávida y con la participación de destacados curadores, teóricos e intelectuales como Stuart Hall, Paul Gilroy, Irit Rogoff y Colin MacCabe.

La 56 Ba Bienal destacó sobre todo por la participación de colectivos multidisciplinarios de zonas poco representadas del mundo. Tal fue el caso de The Propeller Group, grupo basado en Ho Chi Minh City (Vietnam) y Los Angeles e integrado por Phunam Thuc Hac, Tuan Andrew Nguyen y Matt Lucero. The AK-47 vs. the M-16 (Fig. 3) es una video instalación donde dos rifles de guerra utilizados durante la Guerra de Vietnam por los ejércitos de los Estados Unidos y Vietnam, respectivamente, son disparados para capturar el momento en que ambas balas colisionan entre si. La pieza captura dicho impacto de fusión dentro de

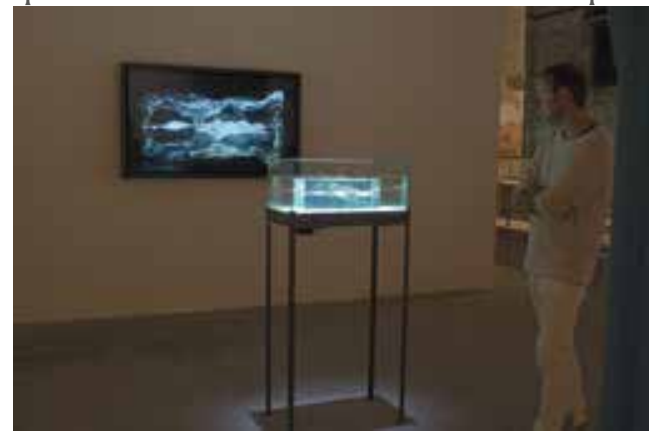

Fig 3. The Propeller Group, (Phunam Thuc Hac, Tuan Andrew Nguyen y Matt Lucero), Ho Chi Minh City (Vietnam) y Los Angeles. The AK-47 vs the M16 (vista de videoinstalación), 2015. Cortesía: The Propeller Group. un bloque de gel transparente que simula la densidad del tejido humano. Un video presenta en cámara lenta el momento en el cual son disparados ambos rifles y cómo se genera, mediante un preciso procedimiento de balística, el impacto entre ambas municiones. La colisión de ambas balas concentra, de forma metafórica, el escenario de la guerra de Vietnam; a nivel escultórico y visual, el bloque de gel donde ambas balas quedan suspendidas de forma orgánica, latente y fuera de control produce una imagen nueva que nos traslada a un hecho histórico. Esta video instalación se complementó con las fantásticas máquinas y armas futuristas alienígenas propuestas por Abu Bakarr Mansaray (Sierra Leone, 1970) (Fig. 4). El carácter artesanal de sus dibujos a lápiz, lapicero y crayones blanco y negro se confronta con la hipermodernidad de sus extravagantes artefactos de ficción. Revive en papel una técnica popular en

9 https://www.youtube.com/watch?v=jhObxGExtT0 
África central basada en producir objetos decorativos y juguetes a partir de fierro, que complementa con diagramas, cálculos y comentarios inspirados en conceptos científicos.

La película Bending to Earth (2015) de Rosa Barba $^{10}$ (Italia, 1972) interviene espacios históricos y pretende construir una narrativa utópica, a partir de imágenes tomadas desde la altura de espacios áridos donde la irrupción tecnológica se percibe minúscula y efímera frente al poder inquietante y avasallador de la naturaleza.

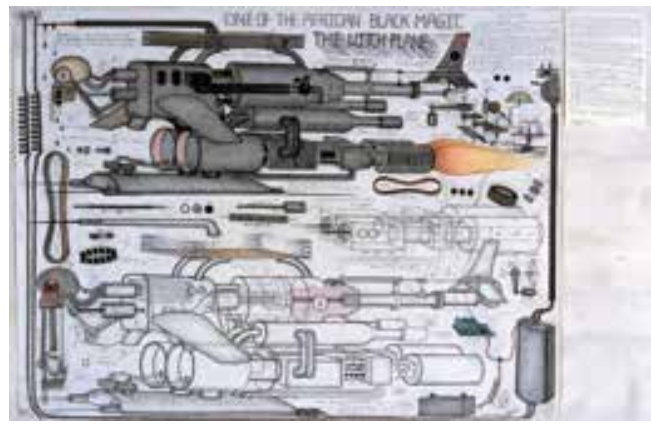

Fig. 4. Abu Bakarr Mansaray (Sierra Leone, 1970). One of the african black Magic. The witch plane (2008). Cortesía: Contemporary African Art Collection - The Pigozzi Collection. Como otras obras recientes de Barba, este trabajo es proyectado en artefactos de cine transformados en esculturas cinéticas que se distienden por el espacio de exhibición y que ponen en evidencia la presencia del celuloide de $35 \mathrm{~mm}$ como un manifiesto adicional sobre la vigencia histórica de este noble formato en épocas de digitalización.

Las cuatro esculturas de madera de Huma Bhabha (Pakistan, 1962) situadas en el centro de una de las salas del Pabellón Central, a toda vista parecieran que son una re-interpretación de imágenes totémicas meridionales que configuran rostros impactantes y con títulos particulares: With Blows (2015), With Words (2015), Mechanic (2015) y Against What? Against Whom? (2014). El joven Ibrahim Mahama (Ghana, 1987) produjo Out of Bounds (2014-2015) una impresionante obra site-specific conformada por sacos de yute usados para transportar carbón. Cosidos entre si de forma irregular a manera de un gran saco, recorrer esta obra a lo largo de los 300 metros del pasillo de acceso al Arsenale genera una sensación densa en el espacio que convierten este gran pasaje en una suerte de epidermis humana desgastada. Mahama, quien emplea a mujeres inmigrantes indocumentadas para coser los sacos entre si, imprime en su obra la explotación generada a partir de la transacción de materia prima en países pobres y que han definido por siglos las reglas de la economía mundial. Estas obras recientes dialogaron inter-generacionalmente con otras históricas como Un jardin d'hiver (1974) de Marcel Broodthaers (Bélgica, 1924), una instalación con 36 árboles Kentia, seis fotografías en blanco y negro y un video que compone la visión historicista y colonialista de los museos universalistas del siglo XIX. También destacó en esta perspectiva la video instalación en tres canales Vertigo Sea (2015) del escritor y cineasta John Akomfrah (Ghana, 1957). Se trata de una reflexión sobre la caza de ballenas, el medio ambiente y la relación del hombre con el mar que combina, de manera sutil e impactante, material de archivo y obra ficcional filmada especialmente para desplegar un diálogo panorámico y universal que pretende sujetar entre sí un componente de ficción a una situación real y latente como es el calentamiento global y su impacto en la naturaleza.

Muchas de las obras seleccionadas para la $56^{\text {a }}$ Bienal analizaron y discutieron las relaciones sociales y laborales imperantes en el mundo moderno, donde las corporaciones privadas han reemplazado en alguna medida el rol de los países y estados. La obra fotográfica de Andreas Gursky (Leipzig, 1955) evidencia las prácticas de trabajo contemporáneas, tanto intelectuales como manuales, desprendiendo una inquietante relación laboral de dependencia que semeja situaciones de semi-esclavitud contemporánea. Un elemento similar de explotación se observó en la compleja video instalación de Mika Rottenberg (Buenos Aires, 1976), NoNoseKnows (2015) vinculada al ritual organizado por trabajadoras de una fábrica

10 http://www.rosabarba.com/ 
en China para transformar las perlas de un insumo natural a un producto de lujo. Ya sea desde una torre en Nueva York o la fábrica de un pequeño pueblo en China, el capital global opera silenciosamente, desarrollando injustas relaciones laborales para fabricar todo tipo de productos de consumo contemporáneo, ya sea material o inmaterial.

La interpretación sociológica fue también puesta en evidencia en las obras actuales e históricas de Hans Haacke (Colonia, 1936), reconocido artista de sistemas, que produce para la Bienal la obra World Poll (2015), un cuestionario de 20 preguntas que invitó al visitante a participar de un muestreo estadístico sobre el sponsorship corporativo de las exhibiciones en museos. Esta obra se confrontaba con otra histórica de Haacke sobre el mismo tema titulada Gallery-Goers's Birthplace and Residence Profile, Part 1 realizada en la Howard Wise Gallery en 1969 donde se les pedía a los visitantes indicar en un mapa datos sobre su lugar de nacimiento y de residencia. Este tipo de obras, que Haacke ha realizado con anterioridad $^{11}$, tienen hoy la capacidad de ser participativas a partir de la facilidad de presentar los resultados en tiempo real o en plataformas online, lo cual genera una mayor percepción sobre el "resultado" de la obra en el público visitante y promueve en forma más evidente una crítica sobre el estado institucional del arte. La obra de Haacke también dialogaba con la instalación Autorretrato. Estructura. Informe. 9.6.72 de la peruana Teresa Burga, a la que aludiremos posteriormente.

Obras históricas como las de Haacke mantienen total vigencia, ya que permiten utilizar el arte como una herramienta activa de interpretación social de la realidad. Muchos artistas articularon la narración de historia(s) mediante el uso de mapas o esquemas para presentar fenómenos sociopolíticos. Tal es el caso de Tiffany Chung (Vietnam, 1969), que presenta Syrian Project (2011-2015), un conjunto de 40 hermosos mapas e infografías dibujados meticulosamente a color con información estadística reciente sobre la crisis en Siria, y otros datos sobre personas desplazadas y campos de refugiados. El trabajo de Chung es una crítica en relación a la decadencia humana, la industrialización y los fuertes cambios que vivimos y guardaba relación con Arts, Crafts and Facts (2015) de Maja Bajevic (Sarajevo, 1967) que utiliza una técnica y estilo de bordado propio de Bosnia para representar gráficos asociados con el capital y la globalización, como son las fluctuaciones de los mercados, variaciones en los salarios y las ganancias corporativas. Desde una perspectiva también historicista, se encuentra el trabajo The Victory Atlas de la peruana Elena Damiani, que mencionaremos posteriormente.

La entrada a la nave del Arsenale nos introdujo a un escenario violento que intercaló la obra en luces de neón American Violence (1981) de Bruce Nauman (Estados Unidos, 1941) donde palabras como Eat, Death, Hate, Pain, Life armonizaban con los conjuntos de dagas clavadas al piso tituladas Nymphéas (2015) de Adel Abdessemed (Algeria, 1971); ambas obras producían una armonía espeluznante que las hacía parecer una sola gran instalación. Mientras tanto, en el mismo pabellón, la obra Paperwork, and the Will of Capital (2015) de Taryn Simon (Nueva York, 1975), presentaba una serie libros abiertos conteniendo de un lado flores planchadas y del otro fotografías de los arreglos florales que estaban presentes durante la firma de acuerdos y tratados históricos. Simon deconstruye así acuerdos políticos trasladando su esencia a un orden basado en la jerarquía herbolaria.

Esta síntesis de la Bienal no puede concluir sin mencionar unas de las obras más comentadas y cargadas políticamente, la perfomance instalación Untitled (Havana, 2000) de Tania Bruguera (La Habana, 1968) donde en un espacio totalmente oscuro y cubierto de paja cuatro hombres desnudos se limpian el cuerpo silenciosamente. El público, en grupos pequeños, debe

11 Véase también MoMA Poll (1970), como parte de la célebre exposición Information organizada en el Museo de Arte Moderno de Nueva York en 1970. 
sortear dicho espacio para llegar a un televisor con imágenes de Fidel Castro respondiendo a preguntas de un periodista. Esta obra es un comentario sobre el control y la represión que viven los cubanos frente a la retórica de una utopía socialista, y resultó significativa considerando que meses antes Bruguera fuera detenida (y su pasaporte confiscado) luego que su performance Tatlins's whisper (2009) fuera censurada por el gobierno cubano.

\section{Pabellones nacionales}

Al igual que es difícil hacer una selección de los artistas participantes en la selección internacional, resultaría irrealizable describir los 88 pabellones nacionales. Cada vez son más los países participantes en la Bienal de Venecia, lo que evidencia la internacionalización de la escena artística contemporánea, exacerbada por la riqueza reciente de algunos Estados emergentes que buscan declarar su existencia (y opulencia), así como también por la necesidad de visibilidad de países diminutos, como la isla Tuvalu (con una población de 12,000 habitantes y un área de $26 \mathrm{~km}^{2}$ ). Dicha isla tocó el tema del calentamiento global desde la perspectiva del incremento de la elevación del mar en pequeñas islas. Algunos pabellones buscaron mostrarse extravagantes, como el pabellón francés con sus "arboles rodantes". Otros, como el pabellón japonés, destacaron por su atmosfera contemplativa, como la instalación The Key in the Hand (2015) (Fig. 5), donde Chiharu Shiota (Osaka, 1972) suspende más de 50,000 llaves en redes enmarañadas entre una telaraña de hilos carmesí a lo largo de un ambiente rojo cruzado por una embarcación de madera. La instalación Processing Nature (2015) del pabellón mexicano se basó en un proyecto de infraestructura que relacionaba los mapas históricos de Venecia y de la Ciudad de México,

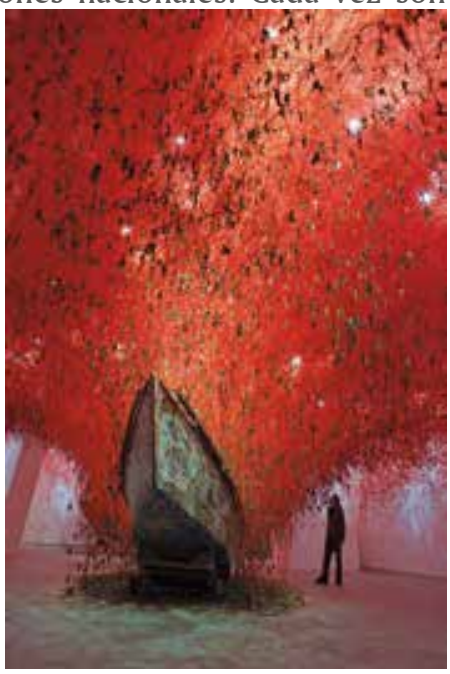

Fig. 5. Chiharu Shiota (Osaka, 1972). The Key in the Hand, (2015). Pabellón Japonés en la $56^{a}$ Bienal de Venecia, 2015. Foto: Sunhi Mang. Copyright: Chiharu Shiota, VG Bild-Kunst. dos ciudades construidas alrededor de canales. Sobre esta base se trazó el recorrido de un canal imaginario entre cada una las sedes que han albergado el pabellón mexicano en Venecia durante los últimos 15 años y que finalmente desembocaba en el actual pabellón. La instalación vinculaba así la tradición "hidráulica" de ambas ciudades con la historia reciente de los pabellones mexicanos. El pabellón chileno presentó una antología de carácter historicista de video y fotografía de Paz Errazuriz (Santiago, 1944). Hito Steyerl (Munich, 1966) presentó la video instalación Factory of the Sun (2015), que resaltaba del resto de las obras del pabellón alemán por su configuración futurista donde los visitantes podían reposar en cómodos chaise longes de playa mientras disfrutaban de un video juego en forma de historia medial sobre nuestro presente digital.

Finalmente, algunos pabellones destacaron por el uso de sus espacios arquitectónicos como base de sus propuestas. La obra Sustainable Identities (2015) de Szilárd Cseke (Pápa, 1967) transformada el pabellón húngaro en un impresionante espacio minimalista donde un objeto móvil esférico navegaba de forma autónoma por las alturas del pabellón. El pabellón de Hong Kong por su lado presentó The Infinite Nothing (2015) de Tsang Kin-Wah (Guangdong, 1976) donde el ambiente fue mediatizado a partir de proyecciones y sonidos donde discurrían frases e imágenes abstractas que reconfiguraban la percepción del espacio.

\section{La participación peruana en la $56^{\mathrm{a}}$ Bienal}

Históricamente, la representación del Perú en Venecia fue siempre limitada, destacando la participación del artista y escritor peruano, residente en Italia, Jorge Eduardo Eielson (en 
los años 1964, 1966 y 1972). La primera participación oficial de un artista en la Muestra Internacional instaurada por Szeemann fue la de Jota Castro. Castro (Yurimaguas, 1965), quien reside en Europa de hace más de treinta años, participó de dicha muestra en dos oportunidades (2003 y 2007). Adicionalmente a ello, es destacable la presencia peruana como parte del Pabellón Latinoamericano organizada por el Instituto Italo-Latinoamericano - IILA, que también permitió la visibilidad del Perú en años recientes con la participación de artistas como Roberto Huarcaya, Carlos Runcie Tanaka, Fernando Bryce, Gilda Mantilla, Luz María Bedoya, Patricia Bueno, Moico Yaker, Sandra Gamarra, Fernando Gutiérrez y David Zink Yi.

Para esta edición dos artistas mujeres peruanas figuraron por primera vez en en la selección de Enwezor: Teresa Burga (Iquitos, 1935) y Elena Damiani (Lima, 1979). Resulta aun más significativo que se trate de artistas en dos estadios muy diferentes de su trayectoria artística: Burga, con una obra conceptual que podríamos definir hoy como histórica y, por otro, Damiani, quien viene produciendo obra desde hace poco más de una década. Es además simbólico y significativo que sean dos artistas mujeres las seleccionadas, pues en el contexto peruano las artistas de género femenino han sido parcialmente discriminadas de la difusión internacional, más aun, cuando se trata de dos mujeres que producen obra dentro de una línea experimental y conceptual que muchas veces resulta poco afín con las exigencias del mercado del arte.

Teresa Burga fue miembro del Grupo Arte Nuevo, colectivo surgido en la década del 60 y que introdujo tendencias vanguardistas, como el arte de sistemas, el arte óptico y la performance en la escena artística peruana. Pese a su retiro de la práctica artística por casi tres décadas, es una de las exponentes más reconocidas del arte no-objetual peruano. En la 56 $6^{\mathrm{a}}$ Bienal, Burga exhibió dos obras, una histórica y otra reciente. La instalación Autorretrato. Estructura. Informe. 9.6.72 (1972) desmonta el autorretrato y lo transforma en un agregador de datos personales mediante diagramas, fotografías y documentación clínica con información real de la autora. Este trabajo producido originalmente en el año 1972 es de total vigencia, pues avizoró las estructuras biopolíticas representadas hoy en los sofisticados agregadores digitales de información personal, como es el caso de Facebook. Adicionalmente a este proyecto histórico, Burga presentó una serie reciente de trabajos en tinta sobre papel donde reproduce eventos de comunicación (desde notas aparecidas en los medios de comunicación hasta dibujos hechos por niños) y que debido al estilo

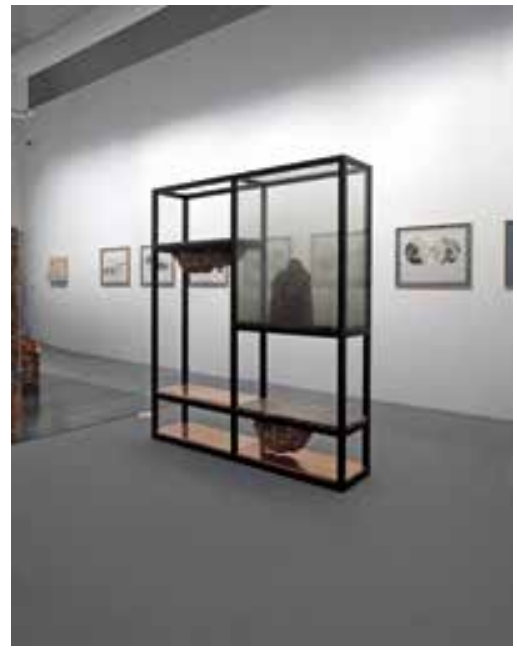

Fig. 6. Elena Damiani (Lima, 1979). Rude Rocks N4 (Turrón after Bratke) (2015). Cortesía: Elena Damiani. puntillista utilizado les otorga una estética casi naif, generando así una fuerte descontextualización de la información. Como bien señala Enwezor en su texto de curatorial, "Burga es parte de una memoria histórica y rescata conceptos que hoy son de primerísima importancia” (Enwezor, 2015b).

Por otro lado, se encuentra el trabajo de Elena Damiani. (Fig. 6) Formada originalmente en el campo de la arquitectura, Damiani es una joven artista que ha explorado múltiples formatos, como el video, el collage, la instalación y la escultura. Su trabajo en Venecia intentó poner en evidencia, a partir del uso de diferentes materiales y técnicas, la re-composición geológica de la materia operando como capas de información que producen nuevas imágenes. La serie Rude Rocks (2015) producida especialmente para la $56^{\mathrm{a}}$ Bienal, está compuesta por conjuntos de esculturas hechas de mármol y travertino peruano, y piezas de cobre y acero crudo. 


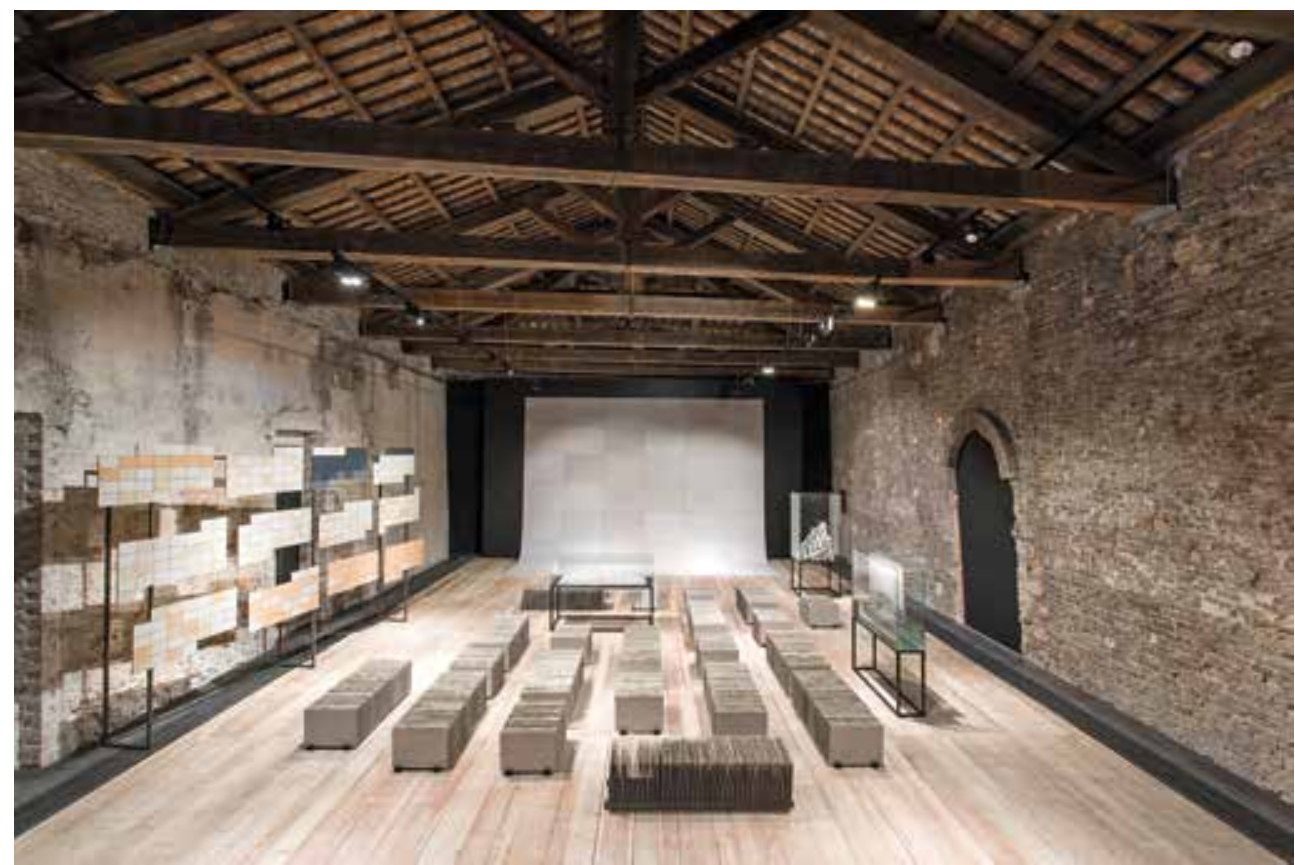

Fig. 7. Gilda Mantilla (Los Ángeles, 1967) y Raimond Chaves (Bogotá, 1963) . Misplaced Ruins "Ruinas Fuera de Lugar" (2015). Pabellón Peruano en la 56 ${ }^{\mathrm{a}}$ Bienal de Venecia, 2015. Foto: Mauro Romanzi.

Dichos conjuntos son un híbrido entre instalaciones y esculturas, que ponen de manifiesto la resistencia física de estas piedras para ser trabajadas y la negación a ser transformadas por el hombre, pues las piedras geológicas aparentan expandirse más allá de las estructuras metálicas que las contienen. La instalación Rude Rocks N4 (Turrón after Bratke) (2015) (Fig. 6) es un complejo ensamble de tres piezas de mármol Breccia dentro de una estructura metálica: dos piezas se encuentran colocadas en posición inversa, desafiando su peso y la otra se deja entrever dentro de una urna de vidrio cuasi opaco. Aparecen así como posibles artefactos que cuestionan la percepción convencional que tenemos acerca de los objetos tornándolos en ambiguos e inaccesibles. La piedra además escudriña la historia como una consecución de capas geológicas que pueden interpretarse como un gran repositorio de información de miles de años de historia y evolución planetaria. También presentó la serie de collages The Victory Atlas (2013), donde el contenido de mapas históricos es intervenido, mediante composiciones geométricas, por imágenes de paisajes naturales y veladuras de papel. Este trabajo cuestiona la función tradicional de los mapas como instrumentos de navegación e ilustraciones de las características físicas de una localidad, e incorpora, como en el caso de otras obras basadas en esquemas visuales presentes en la $56^{\mathrm{a}}$ Bienal, su capacidad para construir narrativas y describir territorios subjetivos.

La participación de Burga y Damiani coincide también con otro hecho histórico: la instauración del pabellón peruano, ubicado en la Sale d'Armi Nord del Arsenale. Curado por Max Hernández Calvo, esta primera edición tuvo a Gilda Mantilla (Los Angeles, 1967) y Raimond Chaves (Bogotá, 1963) como artistas seleccionados con la instalación Misplaced Ruins (Ruinas Fuera de Lugar) (2015) (Fig. 7). Conformadas por cartón reciclado de tonalidades grisáceas en alusión a los colores del monótono y cuasi continuo paisaje costeño, la instalación presenta una serie de "estaciones" interrelacionadas que operan como "traducciones" a referencias locales que van desde la arquitectura, la música y las condiciones climáticas hasta 


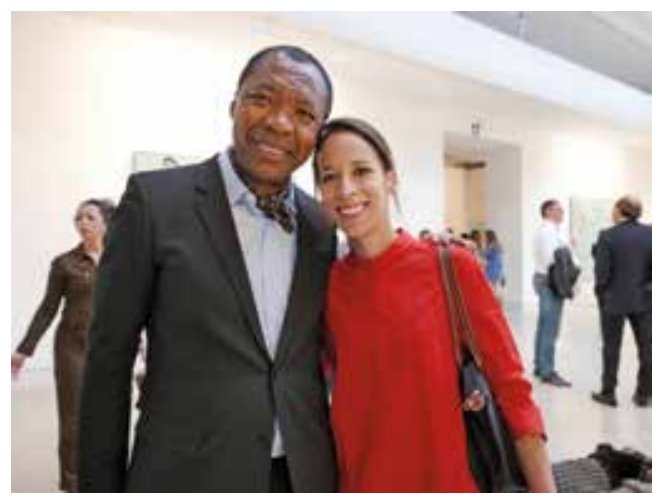

Fig. 8. Okwui Enwezor, curador de la 56va Bienal y Elena Damiani, artista peruana seleccionada. Foto: José-Carlos Mariátegui.

la política ${ }^{12}$. La “estación” central evoca diseños de planificación urbana reminiscentes con sitios arqueológicos costeños o "huacas" pero también resignifican las actuales barriadas limeñas. Un calendario anual simboliza visualmente las condiciones mensuales del cielo limeño y se vincula con un telón al fondo del espacio que también evoca dicho cielo. Sin embargo, los pálidos colores del calendario no sólo hacen reminiscencia al clima meteorológico, sino también al "clima" político: el mes de abril muestra patrones "soleados" debido a la condena a Fujimori, mientras que el mes de junio es visiblemente negro pues hace alusión a la masacre en Bagua o Baguazo $^{13}$. Tres urnas de vidrio también resignificaban algunos elementos puntuales: el cartón húmedo es una evidencia del tiempo climatológico y su proceso cambiante; el cartón destruido y el cartón cortado en forma de billetes trasladan dicha materialidad a procesos sociales. La escalera, único ingreso al pabellón, también cumple con un papel simbólico pues demanda un esfuerzo físico para observar la instalación, similar al esfuerzo que demanda la interpretación con cualquier elemento culturalmente ajeno, en particular en el campo del arte contemporáneo. Una pieza sonora deconstruye una marinera norteña en monotonías abstractas y finalmente, una publicación ${ }^{14}$ presenta textos e imágenes sugerentes que sirven como claves para entender los componentes simbólicos superpuestos a los que hace alusión esta compleja instalación.

El pabellón peruano intentó también insertarse bajo el concepto curatorial de Enwezor: cada "estación" parte de una sutil referencia sobre el "estado de las cosas" en diferentes niveles (climático, social, político, artístico y cultural) y cada pieza ayuda a entender la otra. Al mismo tiempo, las piezas sugieren una irónica ambigiedad sobre el futuro de la sociedad evidenciando también el "fuera de lugar" como un "lugar de lucha" frente a algunos conceptos anquilosados sobre las culturas, tradiciones e historias peruanas.

\section{Conclusión}

Se puede decir que esta Bienal obliga al público a analizar con sentido crítico las obras e involucrarse en sus discursos. Es una Bienal pesimista sobre el futuro de la humanidad, y traslada dicha sensación a obras que atraviesan contextos complejos y locales que son difíciles de descifrar. Sin embargo, Enwezor proclama un estado de las cosas en el mundo en un momento en donde es fundamental recordar la importancia del arte para cuestionar y re-pensar el contexto sociopolítico actual. Es una Bienal donde obras históricas se relacionan con otras recientes en un vaivén de épocas y temporalidades que buscan coincidir con el tipo de reflexión central. El instrumento de dicha reflexión es simbólicamente representado por El Capital, haciendo evidente que hoy dicho texto (y su relectura contemporánea) está más vigente que nunca. Enwezor propone una mirada al pensamiento de Marx en el siglo XXI, incorporando elementos de desarrollo crítico de la cultura para un

12 La obra tiene como referencia un proyecto anterior de los mismos artistas, titulado Observaciones sobre la ciudad del polvo (2010), que recibió la Beca Botín.

13 El 5 de junio de 2009 se llevó a cabo un enfrentamiento entre indígenas, pobladores y la policía de Bagua, una ciudad agrícola de la región Amazonas. En el enfrentamiento, que tuvo como objetivo el desalojo de aproximadamente 5,000 nativos amazónicos en favor de utilizar la zona para la explotación minera, fallecieron 33 personas y se considera como uno de los más significativos atentados en contra de los derechos humanos del segundo gobierno de Alan García.

14 La publicación se puede ver en: http://issuu.com/hongotigre/docs/themisplacedtimes 
diálogo intercultural y luchar así en contra de lo que muchos consideran como una etapa de creciente dominación política y cultural (Dussel, 2005). Es así que la Bienal presenta obras y pensamientos con recursos críticos diversos y propios de cada cultura para elaborar los principios de una nueva modernidad preocupada por los aspectos que Enwezor menciona -como la crisis ecológica, la generación de capital y el impacto tecnológico-. Desde nuestras propias culturas podemos proponer e inventar nuevos principios críticos. Sin embargo, desde otro ángulo la participación de muchos artistas internacionales podría también verse como un fenómeno de expansionismo artístico de zonas poco representadas que muchas veces buscan participar y competir dentro de un mercado de arte global.

Como ya hemos dicho, Enwezor cuestiona el formato de exhibición contemporánea de la Bienal y procura expandirla mediante la incorporación de performances, conferencias y eventos alrededor del tema central para hacerla viva, dialogante y crítica. Le agrega así una mayor dinamización al formato, tornándola en una las bienales más preocupadas por el ámbito social y político actual. No es una bienal en el sentido estricto de lo que configura una exhibición de arte, por el contrario, debe verse como un conjunto de estrategias y recursos que permiten reflexionar sobre el mundo en el que vivimos. Sin embargo, algo que sorprende de esta apuesta curatorial es su limitada propuesta museográfica, sobre todo en el Arsenale donde cada pieza se encuentra dividida en espacios propios, bajo un esquema que limita el intercambio, la asociación e incluso la orientación en el espacio. Maria Lind menciona el parecido de la configuración del espacio del Arsenale con la configuración de los stands de una feria de arte (Lind, 2015). Al ser abierto y de grandes dimensiones, el espacio Arsenale hubiese permitido una apuesta museográfica novedosa, que diste de la forma tradicional en la que fue configurado para la $56^{\text {a }}$ Bienal y aporte al sentido expansivo que Enwezor buscó darle a la exhibición.

Como ya hemos mencionado, la $56^{\mathrm{a}}$ Bienal conjuga obras históricas con recientes, en temas recurrentes que inciden sobre la necesidad creciente y urgente por asumir una postura ética en el arte. Esto hace de la Bienal un espacio dialogante, pero crítico y complejo de entender. Este complejo diálogo se da desde varios ejes, el histórico y el presente, la amplitud internacional en la selección y el carácter discursivo de muchos de los proyectos. Es complejo definir con exactitud lo que Enwezor persigue como resultado de este proyecto, pues el mercado del arte existe y una propuesta curatorial tan ambiciosa corre el riesgo quedar simplemente como un ejercicio intelectual sofisticado, pero sin que este genere un cambio e impacto real en la sociedad.

\section{Referencias bibliográficas}

Dussel, Enrique

2005 Transmodernidad e Interculturalidad (Interpretación desde la Filosofía de la Liberación). México: UNAM.

Enwezor, Okwui

2015a The Akhand Path: To Read Without Stoping. En La Biennale di Venezia. 56th International Art Exhibition. All the World's Futures: 017-117. Venecia: Marsilio Editori.
II A Note on the Special Presentations of All the World's Futures. En Addendum to All the World's Futures. (http://www.labiennale. org/en/art/exhibition/enwezoraddendum/). (2015b) [Consulta: 28 setiembre 2015].

Lind, Maria

2015 "Made to Fit, or The Gathering of the Balloons". e-flux journal \#65 SUPERCOMMUNITY. Mayo-Agosto. 